\title{
Pacifying and Disparity and their relationship to the level of Students Motivation Academic Achievement within Faculty of Physical Education University of Aswan
}

\section{*Dr/ Ehab Jaber Mohamed Gaber}

Introduction and research problem

Psychological factor is a key factor in developing the achievement and aims of sports and stands at the forefront of emotional factors, the emotional factor of the players as one of the psychological factors associated with achieving victory and achievement of sports because emotional attitudes in sports competitions affect the physical condition and the skill and planning of the player as emotion is an integrated response to the organism depends on The perception of the external situation and the physical and physiological changes of the internal organs of the human body.

The motivation of achievement is one of the important aspects in the system of human motives and show this importance in all areas where this highlights the importance in the field of education through the main role of motivation to achieve the achievement of the learning process because it helps to focus attention and delay the feeling of mental stress among students, which leads to increase their collection And their achievement for academic excellence (17:12)

Harash (2001) Rahman alindividuals vary greatly in terms of their reaction to the group to which they belong. Some are very quick in keeping with the criteria of the group, but some find that they do not meet all the criteria and do not follow the individual in all the groups to which they belong

Where the individual has the right not to be lenient. If the proposals of the new or non-conformist on the action of the group have proven their value to members and others in the past, the group gives him the opportunity to express his ideas because others believe that it is in their interest to listen to them.

$\begin{array}{cccc} & \text { Alaa } & \text { Eddin } & \text { Kafafy, } \\ \text { "Safa Al Asar" } & \text { (2000), }\end{array}$

"Lectuer in sports psychology Department, Aswan univerisity Assiut Journal For Sport Science Arts 
agrees that university education is one of the most important educational stages. It represents the top of the educational pyramid and aims to prepare people in an orderly and life-oriented manner.

Therefore, higher education at its levels, especially the university, Care and attention in most developed and developing countries alike, for the important and dangerous role that it plays in the human, social and economic development and the available manpower and leadership of the society, which requires preparation and attention to the human element psychologically and socially, from educational institutions to abstain $\mathrm{P}$ to respond to the modern age and society or interacts with them. (45:10) $\left(\left\{V: Y^{\prime}\right)\right.$. The deep roots of the relationship are the need to belong. People with strong personal needs of belonging tend to be human in different social circumstances, and the extent of accommodation depends on the attractiveness of membership in a particular group, ie on the social rewards derived from belonging. The person does not meet the criteria in those groups that he does not find satisfactory (44:23)

The characteristics of the individuals constituting the group are seen as a component of the personal environment in which the group must operate and the personal characteristics of each member of the group serve as stimuli for all other members, known as social harmony. (94: 4)

The structure of the group consists of a set of interrelated social situations in which a range of advantages are distributed, such as the authority granted by the group to achieve these expectations of the various social potentials. It has been observed that the more important the individual's status is, the more the leader may change the criteria of the group, (46: 8), and it seems to be both different and different.

The process is defined as complex and complex psychological processes resulting from the convergence and convergence of variables, including it is related to the subject of mediation or the group or individual and psychological processes 
related to the counterpart - the opposite of what is the nature of knowledge, including what is an emotional tone and what is a motivation based on the various motives that provoke (8: 5) The attitude of manners, which guide behavior and certain destinations to achieve balance within the individual and between the community and the community.

The motivation for achievement is one of the important aspects of the system of human motivation. It is an essential component in the process of perceiving the individual and guiding his behavior and achieving himself through his goals.

Scientists

and researchers interested in the motivation of achievement such as McClelland have pointed out that the motivation for achievement includes different kinds of behavior, The motivation of achievement in determining the level of individual performance and production in the various fields and activities that he faces. Therefore, the concept of achievement motivation has emerged as one of the distinguishing features of study and research in the dynamics of personality and behavior. Academic in psychological and educational variables and to identify factors that contribute to the interpretation of variation in the motivation of achievement among individuals. (47:21)

In the field of education, the motivation for achievement of students is one of the main concepts that focus on them. Many studies have shown the role of motivation to achieve in the general educational process and the factors and variables that are affected by the motivation of achievement or affect it.

The researcher believes that the importance of the motivation of academic achievement in improving the level of academic and skilled students of the Faculty of Physical Education and the extent of social success of the individual،

The researcher believes that the academic achievement is the real field that gives the student a degree which qualifies him to work in the field of physical education and the application of theoretical and applied sciences studied by this side, and on the other hand acquire personal traits 
effective in his teaching profession or training. (7), (11), (13), (15) and that there is no study dealing with the relationship between coping and other and the motivation of academic achievement and this led the researcher to conduct this study to identify the relationship and different and their relation to the level of motivation academic achievement of students of the Faculty of Education Sports Aswan University.

\section{Research goal}

The aim of the research is to identify the different aspects and their relation to the level of motivation of the academic achievement of the students of the Faculty of Physical Education - Aswan University.

\section{Search queries}

-Is there a relationship between a statistical link between the achievement of academic achievement and the students of the Faculty of Physical Education Aswan University? -Is there a correlation between the statistical achievement among the students of the Faculty of Physical Education, Aswan University?

Some terms in the search Pacifying

\begin{abstract}
The individual is responsible for acting in accordance with the strictness, customs and behavior of the group, and this level responds to the pressure of the group to move in a similar direction to them in a manner that is extreme or exaggerated or opposites or contradictions between what appears and what lies.
\end{abstract}

\section{Disparity}

Avoidance or lack of neutrality or impartiality in the face of the group's rules, beliefs or pressure criteria, which may be exposed either implicitly or explicitly in a direction acceptable to majority rule. (93: 6)

\section{Academic achievement motivation}

The motivation to seek success, achieve a desirable end, or push to overcome obstacles or to finish quickly, to do business well. (3: 1)

\section{Search procedures:}

\section{Research Methodology:}

The researcher used the descriptive method of survey studies to suit the nature of the research and to achieve the target and the research questions.

Society and sample research: 
The research community was in the second year of the Faculty of Physical Education at Aswan University for the academic year (2016/2016). The study sample was chosen by the students of the training department at the Faculty of Physical Education, Aswan University. The total sample was 66 students,) Student to calculate the scientific transactions of the scale, (50) students to apply the basic study of research.

\section{Search tools:}

-Al-Masayra - Al-Mughayira scale prepared by Sabri Attieh, Ibrahim Rabea (2013) (7)

Academic achievement measure. Annex (4)

Search steps:

Survey Study

The researcher

conducted an exploratory study to ascertain the accuracy of the criteria used to apply the sample in question. These measures were applied to a sample of (16) students and non-research sample to conduct scientific transactions for the measurements used in the study.

First: Calibration measure Counter: Annex (2)

- The researcher reviewed the reference to the availability of studies that dealt with the reconciliation - Mgaira (11), (14), (16) as well as the standards of the opposite - the opposite.

- Through the theoretical readings and the reference to the researcher reached the application of the measure of reconciliation and different preparation / Sabri Attia (2013) (7), which includes that the counter - heterogeneity includes three factors: the cognitive factor - the social factor - the behavioral factor.

The scale includes a number of statements that fall under each of these factors, and the number (63) words in its final form.

Second: a measure of motivation Academic achievement:

The researcher has followed the following steps in building and designing the academic achievement measurement form:

-Studying the studies and standards that dealt with the measure of academic achievement (1), (12), (14), (20) whether Arab or foreign, to the extent available to the researcher of these studies and standards. 
-Survey of expert opinions on the factors (axes) that can be the measure of the measure of motivation academic achievement.

-The researcher prepared and formulated the factors related to the academic achievement measure among the students of the Faculty of Physical Education, Aswan University, which were represented in seven factors

-Ambition- fear of not succeeding- self-confidence-

the intensity of emotional control - independence.

\section{Apply basic experience}

The researcher applied the basic study on the basic sample of the students of the Faculty of Physical Education, University of Aswan, the disciplinary division for the academic year (2015-2016). The researcher corrected the forms according to the existing instructions, as explained above according to each scale, in order to solve them in a statistical way. .

\section{View and discuss the results}

\section{Table (1)}

"The correlation coefficient between the level of mediation and motivation for academic achievement in the second year students at the Faculty of Physical Education, University of Aswan"

\begin{tabular}{l|c|c}
\hline \multicolumn{1}{c|}{ Variables } & $\begin{array}{c}\text { Level of } \\
\text { Calibration }\end{array}$ & Level of significance \\
\hline \hline Persistence and ambition & 0.214 & Non-D \\
\hline fear of failure & 0.285 & Non-D \\
\hline Self confidence & 0.301 & Non-D \\
\hline Total score of the scale & 0.3 .21 & Non-D \\
\hline \hline
\end{tabular}

- The value $(\mathrm{t})$ of the scale at the significance level $(0.05)=0.325$

It is clear from Table (1) that there is no statistically significant correlation between the level of motivation for academic achievement and the level of reconciliation. 
Table (2)

"The correlation coefficient between the level of heterogeneity and motivation of academic achievement among students of the fourth year of the Faculty of Physical Education Aswan University"

$\mathbf{N}=\mathbf{5 0}$

\begin{tabular}{l|c|c}
\hline \hline Level of significance & Level of variance & Variables \\
\hline \hline significance & 0.654 & Persistence and ambition \\
\hline significance & 0.665 & fear of failure \\
\hline significance & 0.574 & Self confidence \\
\hline significance & 0.741 & Total score of the scale \\
\hline \hline
\end{tabular}

-The value $(\mathrm{t})$ of the scale at the significance level $(0.05)=0.325$

It is clear from Table (3) that there is a statistically significant correlation between the level of motivation for academic achievement and the level of change.

\section{Discussion of results}

It is clear from Table (2) that there is no statistically significant correlation between the level of academic achievement motivation and the level of reconciliation. The researcher finds that the trait is characterized by a lack of seriousness in taking things seriously, and that the individual perceives that the change in life path through learning The academic aspect is not important and this explains the lack of correlation between the level of reconciliation and the motivation for academic achievement.
Academic excellence is linked to the extent to which students benefit from their psychic abilities in no less than the use of their physical abilities. Psychological abilities help individuals mobilize their physical abilities and energies to achieve the maximum and best performance of the athlete (22: 3 )

The researcher believes that students' motivational levels are affected due to certain motives. This effect is not the same as the growth, but differs from one individual to another. Some respond better when they hear the instructions of the coach or teacher, award bonuses or change the positions of students or players in the game plan or assign the athlete With certain responsibility, or to punish or warn him, are all methods that 
can be used with athletes so it is best to identify the character and nature of the athlete so that we can choose the appropriate means of motivation to use it when needed without resorting to putting all members of the group under the same treatment.

This is in line with what Ibrahim Ghoneim, Mahmoud al-Mutabouli (2015) has pointed out, that the motivation of achievement is one of the most important factors that help man to move forward in life. Achievement is the real weapon capable of restoring self-confidence without any losses. And increase confidence in it is not sound and useful only in one case is to be the owner knew the full knowledge of himself and his abilities and possibilities and circumstances and aware of the most accurate awareness of his personal and personal public position (5: 1)

Thus, it may have been answered the first question, which provides whether there is a correlation relationship is statistically significant between the motivation of academic achievement and the students of the Faculty of Physical Education Aswan University.
It is clear from Table (3) that there is a statistically significant correlation between the level of academic achievement motivation and the level of heterogeneity. The researcher points out that the heterogeneity is characterized by seriousness in taking things seriously, and that the variable person sees change in the life path by learning and the academic side Very important and this explains the correlation between the level of heterogeneity and motivation for academic achievement.

This is consistent with Brunj's (2008) (18) finding of a relationship between the achievement motivation and the academic achievement of the students. The researcher believes that the motivation for academic achievement is a measure of the level of students in the different subjects, and this is consistent with what is indicated by both dreams Naim (2012) (2), Ali bin Mohammed (2006) (13) that motivation helps to complete the process of education.

While the researcher attributed the occupation of self-confidence to the end of the significance of correlation coefficient that the members of 
the research sample were in the second grade in the Faculty of Physical Education, meaning their previous experience in training in previous years, which indicates the decline in the importance of this axis in the significance of correlation coefficient of the level of students in academic achievement.

Thus, it may have been answered the second question, which provides for whether there is a correlation relationship is statistically significant between the motivation of academic achievement and other students of the Faculty of Physical Education Aswan University

\section{Conclusions}

-There is a correlation between the reverse of the statistical significance between the aims of academic achievements and students of the Faculty of Physical Education Aswan University.

-There is a correlation between a positive statistical function between the aims of academic achievement and other students of the Faculty of Physical Education Aswan University. -Achieving a measure of motivation academic achievement in the students of the Faculty of Physical Education Aswan University, which consists of (3) axes (persistence and ambition - fear of failure - self-confidence) include (32) words.

\section{Recommendations}

-Enhancing the level of heterogeneity and progress of students and the spirit of commitment to noble values and norms prevailing in society.

-Designing programs and activities that help to raise students' level of tolerance and diversity.

-To draw the attention of researchers and specialists in sports psychology to the need to conduct studies on coping and variance and linked to other variables.

-Conduct more follow-up studies of the college administration towards the academic achievement of students.

\section{References}

1- Abdulrahman Mohammed Al-Hersh: (2001), "behavior is different and more important to the child's education," Journal of Education, No. 92, Volume II, Qatar

2-Alaa Gamal Al-Sharif (2011) "Negative Approaches and their Relation to the 
Orientation of Psychological Subjects to the Students of AlAzhar University in Gaza in the Light of Self-Determination Theory", MA Thesis, Faculty of Education, Al-Azhar University, Gaza.

\section{3-Alaa Mahmoud Al-Sharawi} (2002), The measure of motivation for academic achievement, Faculty of Education - Mansoura University, Amer for printing and publishing, Mansoura.

4-Alaeddin Ahmed Kafafy, Safa Yousef Al-Assar: (2000) "Emotional Intelligence", Dar Qabaa Publishing and Distribution, Cairo.

5-Ali bin Mohammed Marai Almgami (2006): The motivation of academic achievement and the concern of the test and some academic variables in the students of Teachers College in Jazan, Master Thesis, Faculty of Education, Umm Al Qura University, Saudi Arabia.

\section{6-Asmaa Mohi al-Asadi} (2004): Building a social facilitation standard for university students, unpublished master's thesis, Baghdad University.

7-Atkinson,J.W. \& Litwin, G.H. "Achievement motive and test anxiety" JOURNAL
OF ABNORMAL AND SOCIAL PSYCLOLAGY 2006, 60, 52_36

8-BrownJ.S. The Motivat:on of Behavior. N.Y.: McGraw-HiJl, 2008، pp. 27-50, 180-182.

9-Deepti, H, (2009): Social Intelligence a predictor of positive psychological health, kuru kshetrauniver sity .

10-Dreams of Naim Abdullah (2012), The opposite approach and its relationship to assertiveness and emotional balance among the 11th grade students, PhD thesis, Faculty of Education, Gaza University, Jerusalem.

11- Ender, S.C (2001) "The impact of peer helper training program on the maturity and maturity and self-confidence of under graduate students, Dissertation Abstracts International. Vol. 42. No. 10, April, (p4298-4299).

12-Hisham Ismail Helal (2013) Use of the social network and its relationship to the level of reconciliation and contrast with students of the University of Port Said, published scientific research, Journal of the Faculty of Physical Education, University of Benha

\section{3-Ibrahim}

Ibrahim

Ghoneim, 
Ibrahim Almtaboli (2017)

Effect of motivation academic achievement at the level of field training for students of the Faculty of Physical Education Damietta, the scientific journal of Physical Education and Sports Sciences, Faculty of Physical Education (Male), Helwan University.

14- Majid Mohammed Issa (2009), The impact of a training program for the teacher based on improving the academic self-efficacy of students in the motivation for achievement and the direction of sports in students with learning disabilities, Journal of the Faculty of Physical Education, University of Banha.

15- McKenna, E. (2000). Business psychology and organizational behavior: A student's handbook. 3rd ed., Philadelphia: Psychology press.

16-Omar Ibrahim, Yassin Omar (2004): The Social Coexistence and its Relationship with the Power of the Ego among the First Phase Students in the University, Journal of Duhok University, Vol. (7) (1), Jordan.

17-Kassim. Saull (2001):

Psychology, printed in thelibrary of congress catalog, boston.

18-Sabri Ibrahim Attia, Ibraheem Rabeeh Shehata (2013), "Relationship of social intelligence in parallel and different to the students of the second year of the Faculty of Physical Education Minia University, published scientific research, Assiut Journal of Sports Science and Arts, No. 34, March, Assiut.

19-Rawia Mohamed Hassan: (2009) Human Resources Department, Alexandria, the modern university office.

20-Safaa Tarek Habib (2013)

"The Power of Social Intelligence", Modern University Office, Alexandria.

21-Sayed Ahmed Osman: (2009) "Social Psychology Educational", Faculty of Education, Ain Shams University, Part II, Cairo.

22-Sayed Ahmed Othman: (2002) Social Psychology educational, social normalization and reconciliation - Almguira, Library of Anglo, Cairo.

23-Wilcox, C. (2005). Needs assessment and development of a bullying prevention program for elementary school students. PHD, The State University of New Jersey 